\title{
THE SURGICAL PROGNOSTIC SIGNIFICANCE OF THE ELECTROENCEPHALOGRAPHIC PREDICTION OF AMMON'S HORN SCLEROSIS IN EPILEPTICS
}

\author{
BY \\ W. A. KENNEDY and DENIS HILL \\ BASED ON PATHOLOGICAL MATERIAL SUPPLIED BY \\ J. B. CAVANAGH and A. MEYER \\ From the Institute of Psychiatry and the Guy's-Maudsley Neurosurgical Unit, London
}

In a previous communication (Falconer, Hill, Meyer, Mitchell, and Pond, 1955) the results of treating intractable temporal lobe epilepsy by temporal lobectomy were given. A survey was reported of the clinical, electroencephalographic, radiological, and pathological findings in $\mathbf{3 1}$ cases. The follow-up study of the patients showed beneficial effects upon the epilepsy and upon the personality disorder in a proportion which compared very favourably with most published series. The opinion was expressed that this was due to inclusion of the uncus, Ammon's horn, and possibly the amygdaloid nucleus in the resected tissue. Certainly it is in the anterior and medial structures of the temporal lobe that the main sites of pathological change are found (Earle, Baldwin, and Penfield, 1953; Meyer, Falconer, and Beck, 1954). Their importance in the development of temporal lobe epilepsy is also indicated by experimental work. Thus, in cats Gastaut, Vigouroux, and Naquet (1952) found that alumina cream lesions placed only in the amygdala-uncus regions could induce seizures of the temporal lobe type, and Green, Clemente, and Degroot (1957) also observed such seizures after electrolytic lesions of the medial parts of the amygdaloid complex. It was subsequently shown by both groups independently, as indicated by Green (1957), that Ammon's horn had been severely damaged in these animals. While the part played by Ammon's horn in the genesis of temporal lobe epilepsy is still not clear, in man when its sclerosis is encountered in the excised temporal lobe, diffuse and disseminated damage is also frequently present although usually associated with lesions in other medial and lateral structures. From the clinical point of view the importance of removing the deep temporal lobe structures, including the hippocampus (Ammon's horn), uncus, and amygdaloid nucleus in the operation of temporal lobectomy has also been stressed by Penfield and
Jasper (1954) and recently by Rasmussen (1957)

The diagnostic and pathological data and the therapeutic effects of temporal lobectomy carried out on a larger series of 50 cases are now available and a preliminary report has been given (Falconer, Meyer, Hill, and Wilson, 1957). Following Earle et al. (1953) the pathological findings have been classified in two main groups. While all cases in which a space-occupying lesion could be anticipated orळ clinical, radiological, or electroencephalographie्ष grounds were excluded from the series, there were $\frac{0}{2} \vec{T}$ nevertheless, 14 cases in which very small focat of macroscopic lesions were found in the resecte $B$ 등 tissue, 11 being either very small tumours or glia疋 hamartomas (Group I). In the remainder (36 cases diffuse lesions, of varying degrees of severity, werêt found. In the more severe, sclerosis of Ammon's horn and usually of the other medial structures was present (21 cases, Group IIa); in the less severe, sclerosis of Ammon's horn was not present (15 cases, Group IIb). In the follow-up study it was found that the most striking degrees of benefit as regards fits was seen in the tumours and glial hamartomas of Group I, since all cases were benefited, eight completely so. Of the cases with diffuse pathology (36 patients), those with Ammon's horn sclerosis were benefited to a much greater extent than those without this lesion (Table I). While the relationship between the presence of Ammon's horn sclerosis and relief from fits by surgery is suggested $(P<0.05)$, that between improvement in personality with the presence of this lesion is significant at the $1 \%$ level $(P<0.01)$. It therefore appears that the largest pathological subgroup, constituting over $40 \%$ of the cases with temporal lobe epilepsy submitted to surgery, are those with Ammon's horn sclerosis, and that of those with diffuse lesions, it is in this subgroup that the greatest benefit to the personality disorder and to epilepsy can be anticipated. Indeed 
TABLE I

POST-OPERATIVE IMPROVEMENT IN AMMON'S HORN SCLEROSIS

\begin{tabular}{|c|c|c|c|c|c|c|c|}
\hline \multirow{2}{*}{$\begin{array}{c}\text { Ammon's } \\
\text { Horn } \\
\text { Sclerosis }\end{array}$} & \multirow[t]{2}{*}{ No. } & \multicolumn{2}{|c|}{$\begin{array}{l}\text { Relief* } \\
\text { from } \\
\text { Epilepsy }\end{array}$} & \multicolumn{2}{|c|}{$\begin{array}{c}\text { Improvement } \\
\text { in } \\
\text { Personality }\end{array}$} & \multicolumn{2}{|c|}{$\begin{array}{c}\text { Improved } \\
\text { Working } \\
\text { Ability }\end{array}$} \\
\hline & & + & - & + & - & + & - \\
\hline $\begin{array}{l}\text { Present. . . . } \\
\text { Absent .. }\end{array}$ & $\begin{array}{l}21 \\
15\end{array}$ & $\begin{array}{r}18 \\
7\end{array}$ & $\begin{array}{l}3 \\
8\end{array}$ & $\begin{array}{c}16 \dagger \\
4\end{array}$ & $\begin{array}{r}5 \\
11\end{array}$ & $\begin{array}{r}16 \\
5\end{array}$ & $\begin{array}{r}5 \\
10\end{array}$ \\
\hline
\end{tabular}

* Relief = free of fits (12 cases) or $50 \%$ improved (6)

+ Two pre-operative personalities normal.

were it possible to anticipate before operation that Ammon's horn sclerosis was present on one side, this might strengthen the decision to operate on that side in the anticipation of a good result. The contribution which electroencephalography can make towards this prediction is the subject of the present communication.

\section{Case Material}

Fifty patients submitted to unilateral temporal lobectomy by Mr. Murray Falconer at the Guy'sMaudsley Neurosurgical Unit have been followed up for periods ranging from one to five years. The pathological changes observed in the resected temporal lobes have been reported (Cavanagh, Falconer, and Meyer, 1957) and the relationships between these changes and the clinical factors assessed (Falconer et al., 1957). The principles of selection of cases and the operative technique have been outlined in previous reports (Hill, 1953; Falconer, 1953; Falconer et al., 1955), and the changes in learning ability and of personality studied (Meyer and Yates, 1955; Hill, Pond, Mitcheil, and Falconer, 1957). The present communication reports the results of a correlation study between pathological findings and pre-operative E.E.G. data. The results indicate that on E.E.G. data alone it is possible to predict the presence of Ammon's horn sclerosis in patients suffering from temporal lobe epilepsy.

\section{Electroencephalographic Techniques}

In our previous reports the importance has been stressed of repeated E.E.G. examinations to locate the focus and to determine, in the case of bilateral foci, which is the dominant one. As Gibbs and Gibbs (1947) first showed, the discharges of temporal lobe epilepsy may not appear until the patient sleeps or is narcotized with a barbiturate. Moreover, since the location of the discharges in most cases is on the anterior-inferior surface of the temporal lobe, their identification by the routine methods of scalp electroencephalography may be impossible. In the present series of 50 cases, 212 routine E.E.G.S were carried out pre-operatively. In addition 95 records were made using sphenoidal needle elec- trodes, the patients being narcotized in 34 cases with intravenous thicpentone ("pentothal") and in 53 with oral quinal barbitone sodium ("seconal"); eight cases were examined by sphenoidal electrodes without drugs. Seizures were activated in five cases with intravenous " metrazol ". There were therefore a total of 312 pre-operative E.E.G. investigations.

Sphenoidal Electroencephalograrhy.-Jasper (1949) first mentioned the use of needle electrodes placed in the region of the greater wing of the sphenoid, but the needles were introduced by an anterior approach which can be a difficult procedure. Jones (1951) first described the introduction of such needles by a lateral approach by a method which has been standardized and extensively used in this hospital (Kerridge, 1952). The details of this technique used in 166 patients were reported by Pampiglione and Kerridge (1956). In the present series the spike discharges would have been missed in one case without needle electrodes, but more importantly, in 11 cases independent spike discharges beneath the contralateral temporal lobe would have been missed. As reported earlier (Hill, 1953), the spike discharges may be located at the anterior-inferior part of the temporal lobe (the sphenoidal electrode), at the midtemporal convexity (the ear electrode), in the Sylvian areas, or in the posterior temporal areas ; contralateral discharges may also be present in any of these areas and the spike discharges in ore area may show " spread" to other areas or to the opposite side. Discharges may be evident before the introduction of narcosis, but if not, may appear either in the early or only in the deep stages of narcosis or may only appear during recovery of consciousness. Intravenous thiopentone (" pentothal ") is therefore introduced slowly, the narcosis however, bsing taken to the stage beyond which the corneal reflexes are lost.

Effects of Barbiturate Narcosis on the E.E.G.Narcosis may be necessary to demonstrate the location of the predominant spike focus and its constancy, as well as the presence of other subsidiary spike foci. Of equal importance to the present study is the fact that an intravenous barbiturate induces in the normal cortex of the majority of normal individuals fast rhythm (at 16 to $28 \mathrm{c}$. $/ \mathrm{sec}$.) of moderate voltage, an activity which in the normal brain is symmetrical in frequency and amplitude on the two sides. This fast activity, which appears first in the prefrontal areas, is seen also in all areas of the frontal, central, and temporal cortex in the early stages of narcosis. Pampiglione (1952) was the first to demonstrate the use of this phenomenon for the localization of cerebral lesions, observing that areas of damaged brain failed to show the induced fast 


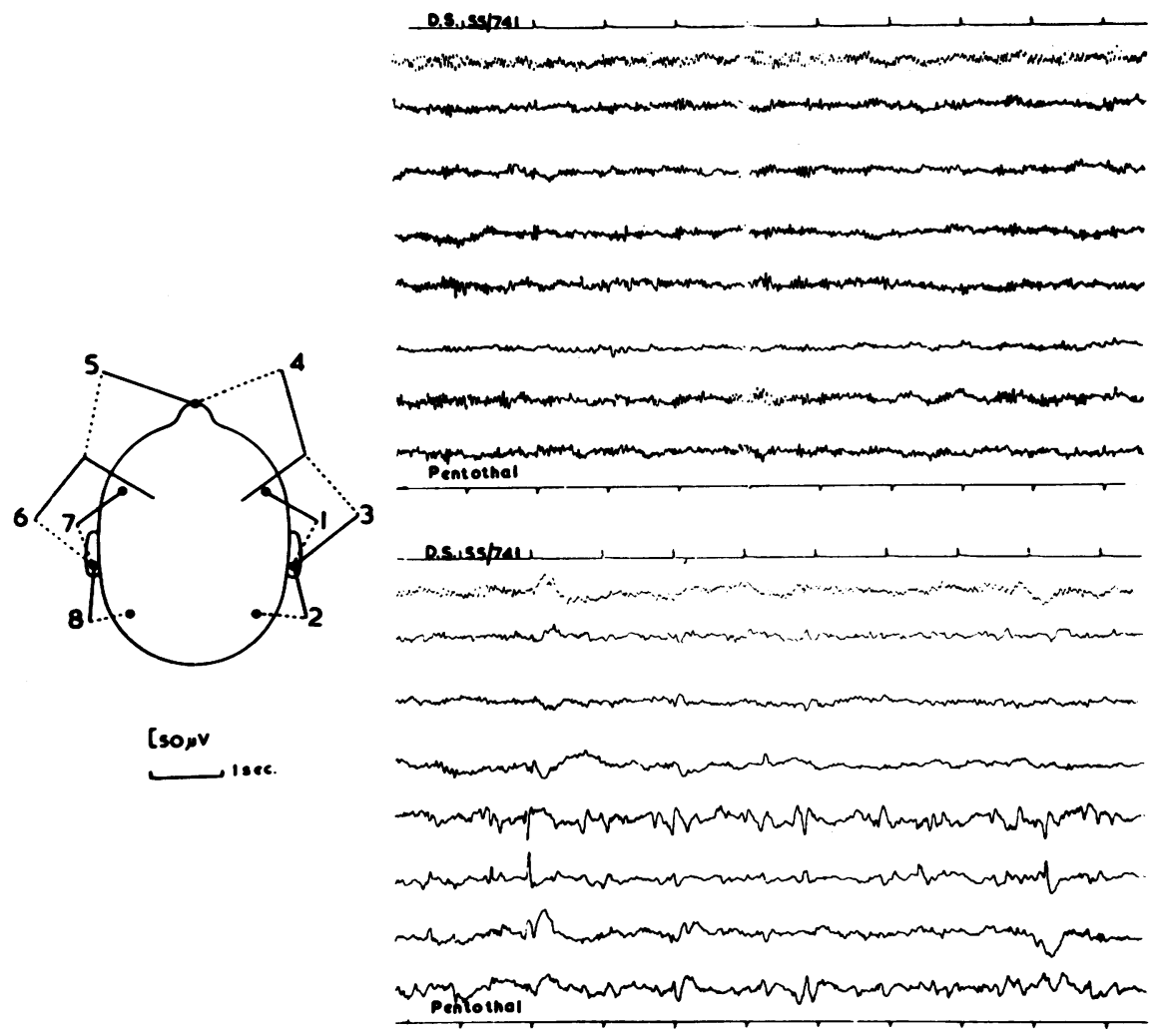

FIG. 1.-Case of left temporal lobe epilepsy with Ammon's horn sclerosis. E.E.G. record using sphenoidal needle electrodes and "pentothal" narcosis. The upper record shows the early fast rhythm stage of narcosis; the lower record is taken during recovery. The electrode schema shows that the first two channels (1 and 2) record from the scalp over the right temporal areas, and the last two channels (7 and 8) record from similar areas on the left side. Channel 3 records between the right sphenoidal electrode and the ear, and channel 6 between the left sphenoidal electrode and the ear. In the upper record channel 6 shows gross reduction of barbiturate-induced fast rhythm in comparison with channel 3 . In the lower record focal spikes are seen only at the left sphenoidal electrode (channels 5 and 6). Thus the left sphenoidal area shows both a reduction of barbiturate-induced fast rhythm and focal spike discharges.

rhythm present in other areas. In the present study, data concerning the symmetry of barbiturateinduced fast rhythm in the temporal areas, as well as in convexity areas, were available in 38 cases. For this purpose the symmetry of rhythm on the two sides was compared from pairs of electrodes, placed on measured positions on the head in homologous situations. In addition comparisons were made of activity recorded between the sphenoidal needles and the nose electrode and, more significantly, between the sphenoidal needles and the ear electrodes (sphenoidal-ear electrodes) on the two sides. The latter observations have proved to be the most significant for the location of temporal lobe pathology (Fig. 1).

\section{Pathological Findings}

The pathological findings in the resected temporal lobes could be divided into two main groups, according to whether focal macroscopic lesions (Group I) were present or whether the lesions were diffuse (Group II). There were 14 cases in Group I, 36 in Group II. The latter were again subdivided into those in which there was Ammon's horn sclerosis (21 cases, Group IIa), and those in which there was no such lesion (15 cases, Group IIb). Detailed histological analysis of all elements available for study in the specimens was made, including assessments as to the extent of involvement of the medial structures (Ammon's horn, uncus, and amygdaloid nucleus), and the cortex and white matter of the lateral, inferior, and fusiform gyri. These findings have been reported (Cavanagh et al., 1957). Sclerosis of Ammon's horn (Group IIa) is rarely found alone, the pathological process almost invariably including the uncus, and, in over a half of the cases in which it was available, the amygdaloid 
nucleus as well. In this group also, the changes in the cortex and white matter were more severe than in the Group IIb, in which the medial structures were relatively spared. It seems probable therefore that Groups IIa and IIb are not distinctive and different pathological entities, but that Group IIa, in which the medial structures are involved, are cases in which the pathological process has been more severe, affecting all elements of the temporal lobe in greater degree than in Group IIb.

\section{Results}

The purpose of this correlation study between E.E.G. characteristics and the data of histological analysis is to find factors in the E.E.G. which will allow prediction of the sites of main pathological change in the affected temporal lobe. Allowance has to be made for the fact that the required data were not available in all cases either from the E.E.G. or the histological work. Table II sets out the results on the numbers available for each item observed for the 50 cases. The main pathological groupings will be considered first.

Group I.-This group of 14 very small focal macroscopic lesions included 11 small tumours and glial hamartomas and three other lesions (two small cortical infarcts and one traumatic scar). Eight of these cases showed a unilateral spike focus and five bilateral spike foci. One case (the only one in the series) showed no spike focus, the operation being performed on other grounds (see Falconer et al., 1955). Barbiturate-induced fast rhythm between the sphenoidal-ear electrodes on the side of the focus was seen to be reduced in two cases and from convexity electrodes in five cases. While there were no E.E.G. features specific to Group I cases, and no features having predictive value, it is of interest that the proportion of strictly unilateral discharges was no greater in this focal lesion group than in the groups with diffuse lesions. In four cases with small tumours spike discharges were evident in the contralateral temporal lobe.

Group IIa.-This group of 21 cases with diffuse lesions were those with marked sclerosis of Ammon's horn as well as other medial structures. In eight cases there was a unilateral spike focus and in a further three spread of the discharges to the opposite hemisphere was observed; in 10 cases the spike discharges were bilateral and fired independently. In 16 of the 17 cases in which it was observed, the barbiturate-induced fast rhythm was reduced between the sphenoidal ear electrodes on the side of

TABLE II

RESULTS OF CORRELATING E.E.G. AND HISTOLOGICAL FINDINGS IN 50 CASES

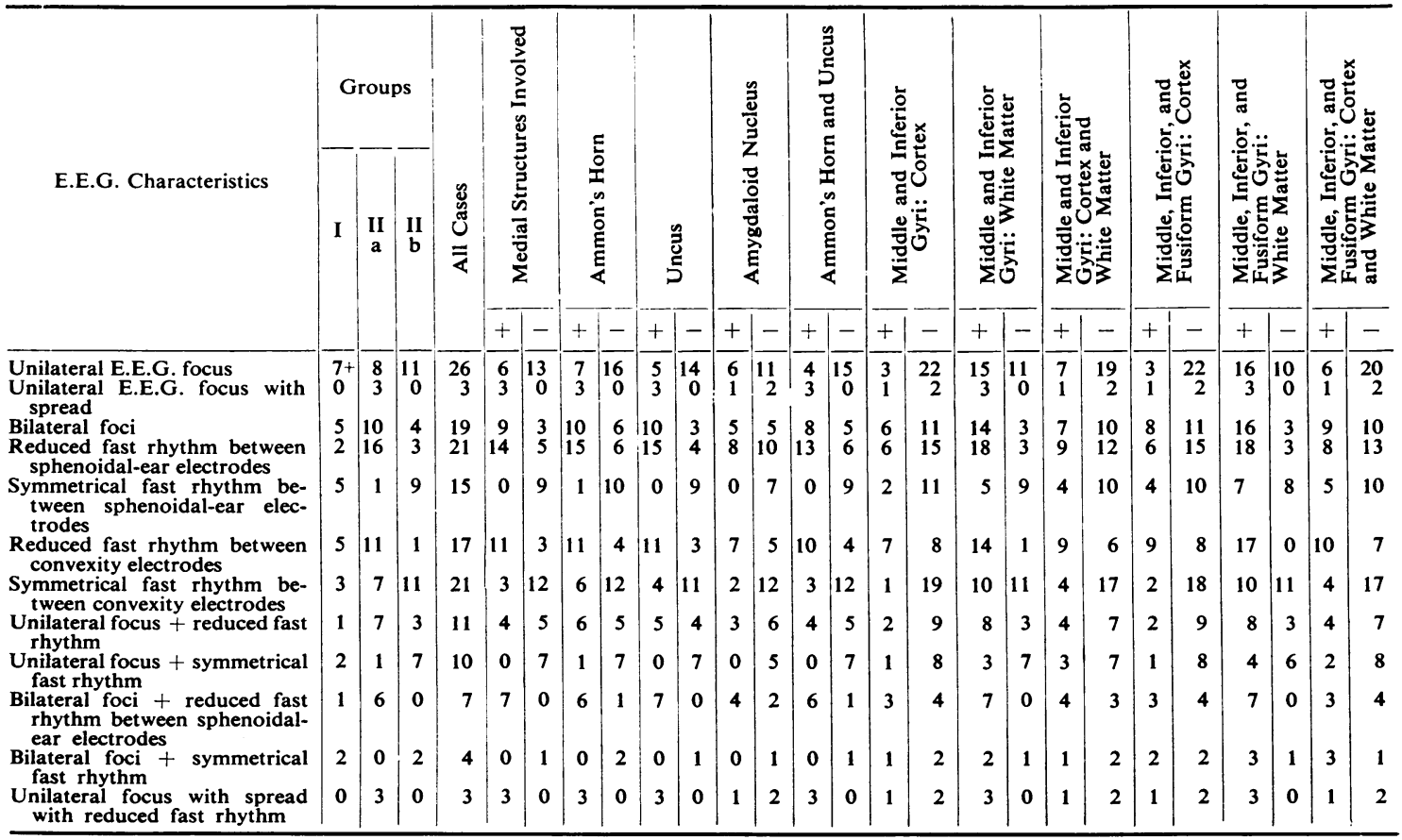

* One case with a unilateral focus has been excluded because no sphenoidal recording was done. 
the focus, and at the convexity electrodes in 11 of 18 cases in which it could be observed. Seven of the eight unilateral cases, the three unilateral cases with spread of discharges to the contralateral side, and the six bilateral cases in which the data were available, showed reduction of the barbiturate-induced fast rhythm between the sphenoidal-ear electrodes on the side of the predominant focus. Thus the finding of reduction of barbiturate-induced fast rhythm beneath the anterior part of the temporal lobe together with unilateral or bilateral spike foci favours the prediction of Ammon's horn sclerosis. The evidence supporting this becomes more precise when the individual medial structures are considered separately (see below).

Group IIb.-In this group of 15 cases with diffuse lesions in which all the medial structures, and in particular the Ammon's horn were spared, 11 showed unilateral and four bilateral spike foci. In contrast to Group IIa cases, in only three of 12 cases was the barbiturate-induced fast rhythm reduced between the sphenoidal-ear electrodes, and in only one of 12 cases at electrodes on the convexity.

The difference between the group with Ammon's horn sclerosis and the group in which this structure was spared, in respect of the fast rhythm response of the temporal cortex to barbiturates, is very striking and has greater predictive value in determining the site of the main pathological changes than any characteristic or location in the temporal areas of the spike discharges themselves. In order to determine which anatomical elements, in addition to the Ammon's horn, are involved in those cases showing this E.E.G. phenomenon, detailed assessments of the degree of pathological change in the various structures were made for all pathological subgroups, i.e., in $\mathbf{5 0}$ cases. For this purpose the degree of involvement for each individual structure was assessed on a four-point scale, namely, $++=3,+=2$, $\pm=1,0=0$ (maximal involvement $=2$ or more, minimal $=1$ or less). This assessment was made for the medial structures (Ammon's horn, uncus, and amygdaloid nucleus) for the cortex and white matter of the middle temporal, inferior temporal, and fusiform gyri, both for cortex alone and for white matter alone. The three medial structures were also considered together (Table II).

Specific Correlations.-In estimating chi square values, in view of the small numbers, Yates's correction was used in all calculations.

(a) Medial Structures (Ammon's Horn, Uncus, and Amygdaloid Nucleus). - If the cases in which spread of discharges from the dominant focus to the contralateral side are included, 12 of 18 cases with maximal involvement of medial structures show bilateral spike foci, whereas only three of 16 with no or minimal involvement show bilateral spike foci. This difference is significant at the $2 \%$ level. On the other hand, all 14 cases of maximal medial structure pathology on which data were available showed reduced barbiturate-induced fast rhythm between the sphenoidal-ear electrodes, whereas of 14 cases with minimal pathology five showed reduced fast rhythm. This difference is significant beyond the $1 \%$ level $(\mathrm{P}<0.01)$. The association of reduction of fast rhythm from convexity electrodes on the scalp over the temporal areas with maximal medial structure involvement is of equal significance $(\mathrm{P}<0.001)$.

(b) Ammon's Horn (Hippocampus).-Considering this structure alone, the associations with bilateral spike foci and with reduction of barbiturate-induced fast rhythm between the sphenoidal-ear electrodes are evident, and the degree of significance is at the $5 \%$ level $(P<0.05)$. This is true in the case of bilateral spike foci; for the reduction of barbiturateinduced fast rhythm beneath the temporal lobe the association is clearer $(P<0.01)$, but the relationship is less clear for the fast rhythm recorded from the scalp electrodes $(P<0.05)$.

(c) Uncus.-Sclerosis of this structure is very clearly associated with bilateral spike foci $(P<0.01)$, $\subseteq$ with reduction of barbiturate-induced fast rhythm ${ }_{\bigcirc}$ beneath the temporal lobe on the affected side $(P<0.01)$, and to a lesser extent with reduction of this activity on the lateral convexity from scalp electrodes $(\mathrm{P}<0.05)$.

(d) Amygdaloid Nucleus.-This structure was available for histological analysis in insufficient cases to enable valid conclusions to be drawn. However, the general trends of association are the same as for the uncus and Ammon's horn, with the exception of the spike foci, since in seven of 13 cases in which this nucleus was involved, the focus was unilateral.

(e) Cortex and White Matter.-Consideration of Table II shows that the more extensive the pathological changes the more likely that the E.E.G. will show bilateral spike discharges and the more likely that barbiturate-induced fast rhythm will be reduced either under or on the lateral surface of the damaged temporal lobe. This is more particularly true of involvement of the white matter than of involvement of the cerebral cortex. Thus of 20 cases showing bilateral spike foci, seven showed involvement of the cortex of the middle and inferior temporal gyri, while 17 showed involvement of the white matter. Of 25 cases with unilateral spike foci, three showed involvement of the cortex and 15 of the white matter of these gyri. Thus with bilateral spike foci there is a greater chance than with a unilateral focus that the cortex will be involved, and a much greater 
chance that the white matter will be so. This association is not, however, statistically significant. The relationship between involvement of the white matter of the temporal lobe and reduction in barbiturateinduced fast rhythm, both beneath the lobe $(P<0.01)$ and on its convexity $(P<0.02)$ is, however, clearly significant, but only at the $1 \%$ level for both observations if the fusiform gyrus is included. Again, therefore, there is evidence that for both E.E.G. characteristics, bilateral spike foci and reduced barbiturate-induced fast rhythm, the greater the involvement of medial structures, either the nuclei or the gyral cortex and white matter, the greater the chances of association with these E.E.G. characteristics.

Surgical Prognostic Significance.-In a previous communication (Falconer et al., 1957) evidence was presented that good therapeutic effects from temporal lobectomy were observed within that subgroup of diffuse lesions in which the Ammon's horn was involved in the pathological changes. This is shown in Table $I$ as regards relief of fits, improvement in personality, and in working ability. These are now considered in relation to the various E.E.G. characteristics described in the pre-operative records (Table III). These show that, for the larger series of 50 cases, contrary to previous indications (Falconer et al., 1955), the unilaterality or bilaterality of the spike discharges has no influence on the therapeutic results, although of course the choice of site for surgery has hitherto depended upon predominant firing. However, one significant observation can be made as regards relief from epilepsy. This is clearly related to the finding of a reduced barbiturate-induced fast rhythm beneath the affected temporal lobe, i.e. between the sphenoidal-ear electrodes. This association is significant at the $1 \%$ level $(P<0.01)$. Reduction of fast rhythm at the convexity electrodes is also associated with a good therapeutic result as regards seizures but only at the $5 \%$ level of significance $(P<0.05)$.

\section{Discussion}

Hitherto the selection of the side for the operation of temporal lobectomy in a patient judged on other grounds to be suitable for the operation has rested largely on the sites of spike foci in the E.E.G. When E.E.G. and radiographic data have been in conflict, the decision has been made upon the former. The decision as to which temporal lobe is involved has been made upon the finding of a predominant spike focus in the E.E.G.s which have been taken upon many occasions. When a unilateral focus has been found at a sphenoidal electrode on every occasion the decision is not in doubt. More frequently, how-
TABLE III

E.E.G. CHARACTERISTICS RELATED TO POST-OPERATIVE IMPROVEMENT

\begin{tabular}{|c|c|c|c|c|c|c|}
\hline \multirow[t]{2}{*}{$\begin{array}{c}\text { E.E.G. } \\
\text { Characteristics }\end{array}$} & \multicolumn{2}{|c|}{$\begin{array}{l}\text { Improvement } \\
\text { in Fit } \\
\text { Frequency }\end{array}$} & \multicolumn{2}{|c|}{$\begin{array}{c}\text { Improvement } \\
\text { in } \\
\text { Personality }\end{array}$} & \multicolumn{2}{|c|}{$\begin{array}{c}\text { Improvement } \\
\text { in Working } \\
\text { Ability }\end{array}$} \\
\hline & + & - & + & - & + & - \\
\hline $\begin{array}{l}\text { Unilateral E.E.G. } \\
\text { focus }\end{array}$ & 18 & 8 & 14 & 12 & 16 & 10 \\
\hline $\begin{array}{l}\text { Unilateral E.E.G. } \\
\text { focus with spread }\end{array}$ & 3 & 0 & 3 & 0 & 3 & 0 \\
\hline $\begin{array}{l}\text { Bilateral foci } \\
\text { Reduced fast rhythm } \\
\text { between sphenoi- } \\
\text { dal-ear electrodes }\end{array}$ & $\begin{array}{l}14 \\
18\end{array}$ & $\begin{array}{l}5 \\
3\end{array}$ & $\begin{array}{l}12 \\
16\end{array}$ & $\begin{array}{l}7 \\
5\end{array}$ & $\begin{array}{l}12 \\
15\end{array}$ & $\begin{array}{l}7 \\
6\end{array}$ \\
\hline $\begin{array}{l}\text { Symmetrical f a s t } \\
\text { rhythm between } \\
\text { sphenoidal - ear } \\
\text { electrodes }\end{array}$ & 5 & 10 & 8 & 7 & 6 & 9 \\
\hline $\begin{array}{l}\text { Reduced fast rhythm } \\
\text { between convexity } \\
\text { electrodes }\end{array}$ & 16 & 1 & 14 & 3 & 14 & 3 \\
\hline $\begin{array}{l}\text { Symmetrical fas t } \\
\text { rhythm between } \\
\text { convexity elec- } \\
\text { trodes }\end{array}$ & 12 & 9 & 8 & 13 & 8 & 13 \\
\hline $\begin{array}{l}\text { Unilateral focus }+ \\
\text { reduced fast } \\
\text { rhythm }\end{array}$ & 8 & 3 & 7 & 4 & 7 & 4 \\
\hline $\begin{array}{l}\text { Unilateral focus }+ \\
\text { symmetrical fast } \\
\text { rhythm }\end{array}$ & 5 & 5 & 3 & 8 & 4 & 7 \\
\hline $\begin{array}{l}\text { Bilateral foci + re- } \\
\text { duced fast rhythm } \\
\text { between sphenoi- } \\
\text { dal-ear electrodes }\end{array}$ & 7 & 0 & 6 & 1 & 5 & 2 \\
\hline $\begin{array}{l}\text { Bilateral foci }+ \\
\text { symmetrical fast } \\
\text { rhythm }\end{array}$ & 3 & 1 & 2 & 2 & 2 & 2 \\
\hline $\begin{array}{l}\text { Unilateral focus with } \\
\text { spread with re- } \\
\text { duced fast rhythm }\end{array}$ & 3 & 0 & 3 & 0 & 3 & 0 \\
\hline
\end{tabular}

ever, contralateral and less active discharges are found and the decision as to laterality has rested upon the relative frequency of the discharges on the two sides. In many cases it is clear which is the predominant side since the relative frequencies may be of the order of $100: 1$, while relative frequencies of the order of $4: 1$ have arbitrarily been taken as the dividing line. The present study indicates that another E.E.G. characteristic, reduction of barbiturate-induced fast rhythm on the inferior surface of the affected temporal lobe, has a predictive significance greater than any other E.E.G. characteristic. This finding was observed in 21 of the 50 patients in respect of the sphenoidal-ear electrodes and in 17 patients from convexity electrodes.

The present study throws further light on the significance of the contralateral and less vigorous spike focus. In five patients with small focal macroscopic lesions in the resected temporal lobe (Group I), contralateral foci were found, and in this group it is reasonably certain that no lesion existed in the contralateral hemisphere. Moreover, the presence in the E.E.G. of bilateral spike foci is found to correlate with maximal pathological involvement of the medial structures and in particular with disease of Ammon's horn and the uncus. Of those patients with diffuse lesions, this group with Ammon's horn 
sclerosis show greater improvement post-operatively as regards fits and personality disorder than those in which these structures are spared. Bilateral spike foci do not therefore exclude a focal single macroscopic lesion but only indicate the probability that whatever the nature of the lesion it is likely to be sited mainly in the medial deep structures of the temporal lobe, and, further, the presence of a contralateral spike focus is not predictive of a poor prognosis for surgery. Thus while 18 of 27 patients with unilateral spike foci were improved as regards epilepsy, 14 of 19 patients with bilateral foci were so.

We can now assess the value of these observations in predicting pre-operatively in which pathological group any given patient's lesions will be found.

Group I (Focal Macroscopic Lesions). - Of these 14 patients, eight showed unilateral foci, five bilateral foci (one no spike focus); two showed reduction of barbiturate-induced fast rhythm at the sphenoidalear electrodes and five at the convexity electrodes. It is not therefore possible to predict this group upon the E.E.G. findings alone.

Group IIa and IIb.--Since the distinction between these two groups is the presence in Group IIa of the main pathological changes in the Ammon's horn, the presence of bilateral foci and/or reduction of barbiturate-induced rhythm beneath the temporal lobe distinguishes Group IIa from Group IIb at the $1 \%$ level of significance.

Falconer et al. (1957) have pointed out that there is a difference in the age of onset of the epilepsy for the different pathological groups. Thus the Group I of focal macroscopic lesions tend to start epilepsy in adult life, and there is no history of abnormal birth or infantile convulsions. By contrast the two groups of diffuse lesions (Groups IIa and IIb) have an onset of epilepsy in early life or a history of birth trauma. It is in the differentiation of these two subgroups that the present study is valuable. The importance lies in the fact that it is those in Group IIa that the greatest therapeutic benefit from temporal lobectomy can be expected (Table I).

The E.E.G. data reported here and the predictions which can be based upon the correlation study with the histological data were available through the use of the sphenoidal-needle-narcosis technique. Without this technique such predictions cannot be made, for without this type of recording the contralateral less active spike focus would have been missed in over $50 \%$ in which it was present. Moreover, the significant finding as regards reduction of barbiturate-induced fast rhythm is that which occurs between the sphenoidal-ear electrodes rather than that which is found to a lesser extent between scalp electrodes over the temporal areas. These observations appear fully to justify the use of this technique.

\section{Summary}

The pre-operative E.E.G. data and the detailed histological data on the biopsy specimens have been studied on 50 patients submitted to temporal lobectomy for the relief of temporal lobe epilepsy.

The technique of using sphenoidal needle electrodes combined with the production of barbiturateinduced narcosis provides E.E.G. data which have predictive value in determining the sites in the temporal lobe of maximal pathological changes.

The presence of a less active contralateral spike focus in the opposite temporal lobe is found to correlate with pathological changes in the uncus and Ammon's horn of the affected lobe at the $1 \%$ level of significance.

Reduction in barbiturate-induced fast rhythm recorded between the sphenoidal and ear electrodes on the affected side correlates with lesions in these medial structures and also in the white matter of the temporal lobe at the $1 \%$ level of significance.

The E.E.G. characteristics in temporal lobe epilepsy can predict the site of maximal pathological change but by themselves cannot predict the nature of that change.

The prognostic implications for temporal lobectomy of the data are discussed.

We wish to acknowledge our indebtedness to $\mathrm{Mr}$. Murray Falconer. We are also indebted to Dr. J. L. Wilson who provided data based on follow-up studies of the patients. We are grateful to Miss K. Spink, E.E.G. recordist.

\section{REFERENCES}

Cavanagh, J. B., Falconer, M. A., and Meyer, A. (1957). Proc. 2nd Int. Colloq. on Temporal Lobe Epilepsy, Bethesda, Maryland. Earle, K. M., Baldwin, M., and Penfield, W. (1953). A.M.A. Arch. Neurol. Psychiat., 69, 27.

Falconer, M. A. (1953). Proc. roy. Soc. Med., 46, 971. Falconer, Hill, D., Meyer, A., Mitchell, W., and Pond, D. A. (1955) Lancet, 1, 827.

Meyer, A., Hill, D., and Wilson, J. L. (1957). Proc. Int. Colloq. on Temporal Lobe Epilepsy, Bethesda, Maryland.

Gastaut, H., Vigouroux, R., and Naquet, R. (1952). Rev. neurol. (Paris), 87, 607.

Gibbs, F. A., and Gibbs, E. L. (1947). Arch. Neurol. Psychiat. (Chicago), 58, 184

Green, J. D. (1957). Proc. 2nd Int. Colloq. on Temporal Lobe Epilepsy, Bethesda, Maryland.

- Clemente, C. D., and Degroot, J. (1957). A.M.A. Arch. Neurol. Psychiat., 78, 259.

Hill, D. (1953).' Proc. roy. Soc. Med., 46, 965

Pond, D. A., Mitcheli, W., and Falconer, M. A. (1957). J. ment. Sci., 103, 18 .

Jasper, H. H. (1949). II Int. E.E.G. Congress, Paris. Rapports. E.E.G. Clin. Neurophysiol., Supp. 2 , p. 99

Jones, D. P. (1951). Electroenceph. clin. Neurophysiol., 3, 100.

Kerridge, J. C. (1952). Ibid., 4, 254.

Meyer, A., Falconer, M. A., and Beck, E. (1954). J. Neurol. Neurosurg. Psychiat., 17, 276.

Meyer, V., and Yates, A. J. (1955). Ibid., 18, 44.

Pampiglione, G. (1952). Electroenceph. clin. Neurophysiol., 4, 79 , and Kerridge, J. (1956). J. Neurol. Neurosurg. Phychiat., 19, 117.

Penfield, W., and Jasper, H. H. (1954). Epilepsy and the Functional Anatomy of the Human Brain, Churchill, London.

Rasmussen, T. B. (1957). Proc. 2nd Int. Colloq. on Temporal Lobe Epilepsy, Bethesda, Maryland. 